\title{
Reflecting on governance for CMAJ
}

Early release. Published at www.cmaj.ca on May 2, 2006.

$\mathrm{E}$ ditorial independence in scientific journals has again emerged as a fundamental issue for discussion as a result of recent events at $C M A J{ }^{1-3}$ Editorial independence is not a simple concept. How does it relate to the journal's mission? Who defines the mission? To whom, for what and how should the editor be held accountable? How are disputes between the editor, sponsoring organization and the publisher best resolved?

In response to the recent events, the CMA made meaningful changes in the interim governance structure for $C M A J$ and named the Right Honourable Antonio Lamer to chair the Governance Review Panel, which is due to deliver an interim report by the end of May and a final report in July 2006.,5

As the interim stewards for CMAJ, motivated to sustain and protect the journal, we cannot overstate our strong belief that editorial independence is the sine qua non for any scholarly journal. Without it, $C M A J$ will not maintain or deserve its position as Canada's premier peer-reviewed general medical journal. However, questions remain about what editorial independence means and whether limits should be placed upon it. Indeed, the situation at $C M A J$ has prompted the Executive of the World Association of Medical Editors (WAME) to ask its Editorial Policy Committee to review its current ${ }^{6}$ statement on editorial independence to determine whether there should be limits to that independence.

In this editorial, we raise questions that we believe to be central to editorial independence policies and governance structures. These are questions we struggled with in preparing our submission to the Lamer review panel (www.cmaj.ca)

Editorial independence and the mission of a journal are linked. Hence, how should $C M A$ 's mission be established and maintained over time? What are the respective roles of the editor, the CMA and the publisher in defining the mission? Since $C M A J$ is a benefit of membership in the CMA, should members have a role in defining the journal's mission? If so, how best can their views be realized given the wide spectrum of CMA members (i.e., urban, rural, remote, academic, community-based, researchers, clinicians, educators, administrators and patient advocates)?

Once $C M A F$ 's mission has been defined, who decides on its interpretation? Does editorial independence extend to editorial decisions and actions that are inconsistent with the journal's mission? If disagreements occur, what adjudication process should be undertaken and by whom?

Should limits exist on editorial independence relating to editorial perspectives, agendas, biases and interests? Although editors must have independence, we realize that they have their own perspectives, opinions and interests. $C M A J$ requires authors to list potential conflicts of interest and to outline study biases and limitations, and it requires rigorous peer review of all research articles and reviews, taking into account biases, stated conflicts of interest and study limitations. Should requirements for peer review and declarations of conflicts of interest be made for all other editorial content in the journal? Should any oversight scrutiny be applied to editorial decisions about journal content, and if so, what and by whom?

Editorial independence should not confer immunity from accountability. Even while exercising independence, the editor must still be held accountable for adherence to $C M A F \mathrm{~s}$ mission and for the responsible exercise of editorial authority. But to whom is the editor accountable? Is it appropriate to hold the editor most accountable to the readers, and if so, would this be to readers who are members of the CMA, to the general readership in Canada or to international readers? Alternatively, is it more appropriate to hold the editor accountable to the CMA or the public?

Once $C M A$ 's mission and lines of accountability are identified, how can the need for both editorial independence and accountability be balanced? The choice of governance structure requires exquisite sensitivity to these issues.

Answers to these questions will help not only future $C M A J$ editors, the CMA and the publisher and strengthen the journal, but they will also help other journal editors and their publishers. We invite readers to engage in this critical dialogue. - Noni MacDonald, Acting Editor-in-Chief; Bruce Squires, Editor Emeritus; Jocelyn Downie, Advisor to the Interim Editorial Board; and the Interim Editorial Board: Arnold Aberman, Paul W. Armstrong, Frank Davidoff, Allan Detsky, Judith Hall, Brian Hennen, Jean Rouleau, Claude Roy, Jeff Scott and Donna Stewart

\section{REFERENCES}

I. Kassirer JP, Davidoff F, O'Hara K, et al. Editorial autonomy of $C M A J$ [editorial]. CMAJ 2006;174(7):945-50.

2. Choi S, Flegel K, Kendall C, et al. A catalyst for change [editorial]. CMAJ 2006; I74(7):90I.

3. MacDonald N, Squires B. Why we agreed to step into the breach. CMAJ 2006; I74(8):1063.

4. Canadian Medical Association. CMAJ editorial governance principles. Available: www.cmaj.ca/pdfs/governance.pdf (accessed 2006 Apr 24).

5. Collins-Nikai R. CMAJ: moving forward [e-letter]. Available: www.cmaj.ca/cgi/eletters ?lookup=by_date\&days=2I\#I74/8/1063-a (accessed 2006 Apr 24).

6. World Association of Medical Editors (WAME). Editorial independence. Available: www.wame.org/wamestmt.htm\#independence (accessed 2006 Apr 24). 